\title{
ARTIGOS
}

Submetido 24.12.2018. Aprovado 14.12.2019

Avaliado pelo sistema double blind review. Editor Científico: Mauricio Reinert

Versão original

DOI: http://dx.doi.org/10.1590/So034-759020200404

\section{IMPROVISAÇÃO: NEM JAZZ, NEM TEATRO, MAS METAMORFOSE ITINERÁRIA}

\author{
Improvisation: Neither jazz nor theater, but itinerant metamorphosis \\ Improvisación: Ni jazz ni teatro, sino metamorfosis itineraria
}

ALEXANDRE DE PÁDUA CARRIERI ${ }^{1}$ aguiar.paduacarrieri@terra.com.br 0000-0001-8552-8717

\section{EDSON ANTUNES QUARESMA JÚNIOR²}

edsontunes@hotmail.com

0000-0001-9450-9753

\section{JOSÉ VITOR PALHARES}

titopalhares@hotmail.com

0000-0002-9190-3875

ANA ROSA CAMILLO AGUIAR ${ }^{1}$

rosacamillo@gmail.com

0000-0001-6488-5651

${ }^{1}$ Universidade Federal de Minas Gerais, Centro de Pós-Graduação e Pesquisas em Administração, Belo Horizonte, MG, Brasil

${ }^{2}$ Instituto Federal do Norte de Minas Gerais, Montes Claros, MG, Brasil

\section{RESUMO}

O objetivo deste artigo foi compreender como a improvisação realizada pelos artistas circenses se insere no cotidiano da gestão do circo e do espetáculo. Sob a perspectiva qualitativa de investigação aplicada na análise de multicasos, os dados foram produzidos mediante observações assistemáticas no cotidiano de 31 circos itinerantes localizados na região sudeste do Brasil e de entrevistas semiestruturadas com 116 artistas circenses, e a análise de dados foi feita por meio da análise de narrativas. As improvisações aparecem tanto na condução do espetáculo como dentro deste. Elas estão vinculadas ao poder de afetar ou não o público que assiste às peças e de preencher um vácuo na condução da performance circense, que cria condições para possíveis enredos. 0 espetáculo se metamorfisa, então, em várias possiblidades: encurtando, empurrando, apressando, picotando. Agenciamentos esses que possibilitam maliciosamente a improvisação de ocorrer, desenhando outros espetáculos.

Palavras-chave | Improvisação, circo, gestão, agenciamento, Deleuze.

\section{ABSTRACT}

This article aims to understand how the improvisations performed by circus artists fit into the daily routine of circus and show management. Applying the qualitative research approach to multiple case analysis, data were collected through asymmetric observations of the routine of 31 traveling circuses in southeastern Brazil and semi-structured interviews with 116 circus artists. The data were analyzed using the narrative analysis method. The improvisations occur in both the management and performance of the circus show and are linked to its power to affect (or to not affect) audiences and fill a void in the conduction of the circus performance, which creates the conditions for potential plots. Therefore, the circus spectacle morphs into various possibilities, whether shortened, expanded, rushed, or split into parts, and these assemblages maliciously allow the occurrence of improvisations and different show designs.

KEYWORDS / Improvisation, circus, management, assemblage, Deleuze.

\section{RESUMEN}

El propósito de este artículo fue comprender cómo la improvisación realizada por los artistas circenses se inserta en la rutina diaria de la gestión del circo y del espectáculo. Desde la perspectiva cualitativa de la investigación aplicada en el análisis multicaso, los datos se produjeron a través de observaciones no sistemáticas de la vida cotidiana de 31 circos itinerantes de la región sudeste de Brasil y de entrevistas semiestructuradas con 116 artistas circenses, y el análisis de datos se realizó por medio del análisis de narrativas. Las improvisaciones aparecen tanto en la conducción del espectáculo como dentro de este. Están vinculadas al poder de afectar o no al público y de llenar un vacío en la conducción de la performance circense, lo que crea condiciones para posibles tramas. El espectáculo entonces se transforma en varias posibilidades: acortadas, expandidas, apresuradas o desmembradas, y estos agenciamientos permiten maliciosamente la aparición de improvisaciones y diferentes modelos de espectáculos.

PALABRAS CLAVE / Improvisación, Circo, Gestión, Agenciamiento, Deleuze. 


\section{INTRODUÇÃO}

Este artigo busca fazer uma reflexão sobre a gestão e a improvisação. Tendo como pano de fundo nossas observações deleuzianas de que as relações sociais (de poder) propiciam às pessoas criarem, astuciosamente, formas de estarem no mundo (Deleuze, 2006, 2013; Deleuze \& Guattari, 1997), o objetivo que norteou este artigo foi compreender como a improvisação realizada pelos artistas circenses se insere no cotidiano da gestão do circo e do espetáculo, criando formas de percorrer o mundo. Tentamos nos aproximar da gestão cotidiana dos circos itinerantes da região sudeste do Brasil, o que evidenciou uma busca mais pelas diferenças do que pelas regularidades, mais pelas novidades do que pelas estabilidades.

Apesar de ser um conceito complexo, interdisciplinar e que admite diferentes significados, a improvisação geralmente está associada à noção de a intuição orientar ações de maneira espontânea (Crossan \& Sorrenti, 2002), levando-se em consideração aspectos como novidade, recursos limitados, conhecimento, espontaneidade e flexibilidade. Vale ressaltar que o improviso tem sido cada vez mais reconhecido como um tema de pesquisa importante na Administração, sendo o trabalho de Weick (1979) considerado um dos primeiros a darem atenção especial à improvisação nas teorias de gestão (Leybourne, Lynn, \& Vendelø, 2014). No entanto, estudos empíricos e estruturas conceituais que abordem o assunto ainda são escassos, demonstrando, então, uma fragilidade no campo (Hadida, Tarvainen, \& Rose, 2015; Leybourne et al., 2014; Vera, Nemanich, Vélez-Castrillón, \& Werner, 2016). Além disso, a literatura sobre improvisação tem se concentrado em antecedentes, no tipo de estímulos e na tipificação de constructos, dando pouca atenção ao seu processo (Abrantes, Passos, Cunha, \& Costa, 2018). Destaca-se, ainda, que os estudos no Brasil sobre a temática se restringem, sobretudo, ao contexto organizacional tradicional e principalmente ao âmbito teórico, sendo escassos estudos com investigação empírica (Arantes, Freitag, \& Santos, 2018).

Desse modo, este artigo mostra-se relevante para a área, uma vez que busca preencher tais lacunas e avançar nas discussões sobre improviso, temática essa que tem se mostrado cada vez mais importante, pois se subscreve num momento de crises financeiras internacionais e mudanças sociais, e que, portanto, pode auxiliar a compreensão dos processos organizacionais em momentos de turbulência, onde o improviso é relevante até mesmo para sobrevivência do negócio. Também se justifica teoricamente pela expansão dos estudos sobre o improviso, estabelecendo conexão entre o tema e autores como Deleuze e Guattari, bem como por dar continuidade à busca por estruturas intermediárias que envolvam o improviso, como proposto por Cunha, Clegg, Rego e Neves (2014) e Cunha, Clegg, Rego e Story (2013).

Tradicionalmente, as pesquisas sobre improvisação nos Estudos Organizacionais estão associadas ao conceito de metáforas, principalmente as do jazz e do teatro. Contudo, como apontado por Zourabichvili (2005), acreditamos que o uso metafórico, apesar de facilitar a compreensão e a aparência, busca criar pseudoconceitos pelos quais nos fazem ver a gestão sob a forma de modelos, escrita e pensamento de uma classe social, de um mainstream administrativo. Para esse autor, assim como para Deleuze, a metáfora é, então, um embuste, pois ressoa, em uma única imagem, o mundo em sua riqueza e complexidade. A metáfora guiaria nossos sentidos, criaria uma imagem que se atualiza nela mesma, simplificando a realidade deste mundo.

Visto isso, utilizamos como base a compreensão do saberfazer circense e as contribuições de Deleuze, e trouxemos o conceito de metamorfose para pensar a improvisação. DeLuca, Rocha-de-Oliveira e Chiesa (2016) e Kravchenko (2017) trabalham o conceito de metamorfose e aproximam-se das reflexões de Deleuze e Guattari (1997), quando apontam o campo de possiblidades que aparecem ao sujeito. "Trata-se de algo que é dado, mas que passa, ao mesmo tempo, por ressignificações em diferentes contextos, demonstrando o potencial de metamorfose do indivíduo" (DeLuca, Rocha-de-Oliveira, \& Chiesa, 2016, p. 460). É nesse sentido que trabalharemos o tema da improvisação e da gestão, isto é, como campos de possibilidades que aparecem aos sujeitos a partir de processos sócio-históricos e os fazem criar novos sentidos.

É importante destacar que partimos aqui do entendimento de que a realidade é um complexo de forças em constante interação e, nesse sentido, seu funcionamento se daria a partir de dois planos - o plano de organização (ou molar) e o plano da imanência (ou molecular). Enquanto no primeiro plano predominam as linhas duras (linhas cristalizadas, estratificadas e viabilizadoras das normas e padrões) responsáveis pelas normas e pela perspectiva binária dos fenômenos (certo e errado; homem e mulher; arte e gestão), no segundo predominam os fluxos de forças capazes de fazer emergir a diferença, o novo, a vida. Os autores entendem a importância da existência dos dois planos, mas problematizam os riscos de um endurecimento progressivo do plano de organização, esvaziando os espaços para a imanência, para o diferente e a circulação da vida (Deleuze \& Guatarri, 1995a, 1995b). Do ponto de vista organizacional, uma leitura possível é de que isso significa, cada vez mais, privilegiar os modelos estruturados de gestão em detrimento das perspectivas mais inventivas da gestão cotidiana. 
A itinerância dos circos estudados faz com que os sujeitos circenses possam alterar projetos ao longo de suas trajetórias, negociando sua realidade, contemplada por outros projetos de indivíduos ou grupos encontrados pelo caminho. Parker (2011), Quaresma, Silva e Carrieri (2014) e Aguiar e Carrieri (2016) demonstram que, sem ponto fixo nem sede a quem recorrer, a gestão dessas organizações se metamorfisa às relações de poder, às condições do terreno e às imposições legais de órgãos municipais, à falta de público, às condições climáticas etc. E, ao mesmo tempo, a improvisação apoia-se na tradição da arte circense, no fazer-saber de quem vive e trabalha no circo, interagindo com os mais variados públicos. A improvisação é "resultado" dessa interação com o social e do (re)conhecimento possível que mostra uma situação de necessidade e de algo a ser inventado.

\section{NEM MÚSICA, NEM ENCENAÇÃO: TRANSFORMAÇÃO COMO BASE DA COMPREENSÃO DA IMPROVISAÇÃO}

Usualmente, o artifício principal utilizado para encontrar a improvisação nas organizações são as metáforas. Para Cornelissen (2005) e Cassell e Bishop (2018), as metáforas são um recurso valioso para o desenvolvimento de conhecimento, principalmente para a área de Administração e as teorias organziacionais. Nos Estudos Organizacionais, muitas vezes as referências à metáfora aparecem para que os autores façam determinadas interpretações, para um efeito didático, crítico e até mesmo para adequação de um contexto histórico. Sanabria e Moreno (2018), por exemplo, ao pesquisarem o campo da estratégia organizacional, trazem a improvisação como tema primordial, contrapondo o conceito de planejamento ao da improvisação musical.

A metáfora do jazz é uma imagem comumente utilizada para se refletir sobre a improvisação (Cunha, 2002; Flach, 2012; Weick, 2002). Nesse sentido, há vários estudos que se utilizam dessa metáfora para fazer a ponte entre a improvisação musical e a gerencial. Deve-se ressaltar, todavia, que a metáfora do jazz traz consigo uma forte carga de elitismo e de sexismo (Hatch \& Weick, 1998). A ideia de elitismo estaria ligada à produção de conhecimento apreciado e entendido por determinada classe social. Já a ideia do sexismo associa-se à reprodução machista/ patriarcal em que o homem branco tem primazia da improvisação.

Outra metáfora frequentemente utilizada nos estudos sobre improviso é a do teatro, na qual se acredita que a improvisação trata mais de pensar a estrutura como lugar onde a improvisação acontecerá, por meio dos diversos processos (Vera \& Crossan, 2004). Para Buras (2017), houve ganhos pela adoção da metáfora do teatro em detrimento daquela do jazz. A metáfora do teatro estaria ligada a um coletivo, ao desempenho do grupo, e não somente à performance de um indivíduo, como quase sempre está relacionada a metáfora do jazz.

Recentes publicações (Afkhami \& Shakiba, 2018; Müller, 2018), todavia, têm endereçado críticas às duas correntes demonstradas. Nessas publicações, evidencia-se que a questão não seria a tipologia da metáfora em jazz ou teatro, mas sim as limitações na explicação dos processos de improvisação devido à própria adoção de metáforas. As metáforas seriam formas ingênuas de abordar o tema, uma vez que nenhum improviso é neutro politicamente e a metáfora se trata de uma simplificação do que seria o cotidiano organizacional. Além dos usos e abusos no sentido de simplificação das relações sociais, o uso de metáfora também é visto como uma forma de dominação ou opressão, e tal prerrogativa está sendo utilizada para desqualificar outros tipos de conhecimento que não seja o científico, e, mais precisamente, o conhecimento do mainstream administrativo.

Para Deleuze (2013), as metáforas retratariam visibilidades e enunciabilidades historicamente datadas. De acordo com o autor, a metáfora seria produto de uma formação histórica que se define por sua verdade discursada e que tem por base um regime de enunciados próprios. Assim, a imagem da metáfora se referiria a certa maneira de ver um objeto, que, ao ser enunciado, vai gerar uma classificação, norma, definindo esse objeto naquele momento e lugar. Nesse sentido, as visibilidades são as condições, pois tudo que se faz em uma época supõe um regime de luz e tudo que se pensa em uma época supõe um regime de enunciados e de verdades.

Desse modo, pensar a improvisação como metamorfose pode nos ajudar a pensar também a gestão (do cotidiano) como possibilidades de transformações. Autores como Costa (2006) evidenciam que podemos pensar com Deleuze e Guattari (1997) em uma ética da improvisação, isto é, a partir da ideia de uma continua improvisação cotidiana, em que os sujeitos experimentariam continuadamente atos criativos que advêm da busca pela sobrevivência.

Para esses autores, imprevistos podem oportunizar um campo de possiblidades que aparecem nas interações cotidianas. É nesse campo de possibilidades, segundo DeLuca, Rocha-deOliveira e Chiesa (2016), que os sujeitos podem alterar suas trajetórias, seus planos, suas decisões e criar novas formas, novas atuações, novas gestões, “quando uma série de possíveis se esgota e o impossível é atingido, tudo se transforma em acontecimento, cada movimento é uma metamorfose" (Agostinho, 
2017, p. 620). É importante destacar que, conforme explicitado anteriormente, a improvisação predomina no nível molar (plano da imanência) que atravessa o plano da organização. Nesse sentido, vale retomar a ideia deleuziana de que a arte não se refere à criação de formas ou reprodução das já existentes, mas de captar forças que, livres em fluxo, podem viabilizar o novo, o diferente (Deleuze, 2006).

Vale ressaltar que não estamos falando, aqui, da metamorfose como em Kafka (2000), “onde o peso do sofrimento no trabalho repetitivo e os efeitos da precarização do emprego em uma sociedade da pasteurização dos atos, destituídos de sentido, carregados de automatismos e repetições enfadonhas" (Soler, 2016, p. 133), em que as relações contemporâneas de trabalho culminam quase que, necessariamente, na massificação e eliminação dos espaços de criação. Neste artigo, pensamos a metamorfose como transformação criadora, baseada em possiblidades que são criadas a partir das ações dos sujeitos (circenses).

A improvisação teria por base a apropriação por parte dos sujeitos desse campo de possibilidades (e de impossibilidades) que acontecem e se esgotam no cotidiano. O imprevisto produziria uma desterritorialização do sujeito, mesmo que seja momentânea, e a improvisação pode reterritorializá-lo (no antigo território) e até produzir uma neoterritorialização (novo território). Deleuze e Guattari (1997), nesse sentido, falam sobre os aspectos da territorialização no sentido de transformação do significado dado pelos sujeitos ao seu cotidiano, à sua realidade.

É importante destacar que esse processo de territorialização (des e neo) ocorre em meio aos agenciamentos, que são, basicamente, o processo de encontro das forças que compõem a realidade. Nesse sentido, esses encontros podem, de um lado, endurecer formas de vida já estratificadas (leis e normas estabelecidas) ou, por outro lado, viabilizar novas e outras formas possíveis (Deleuze \& Guattari, 1997). Nesse sentido, conforme Zourabichvili e Goldstein (2004, p. 16), os agenciamentos podem levar a formas sociais relativamente estáveis com um funcionamento reprodutor que reduzem o campo da experimentação, definindo para o indivíduo formas socialmente disponíveis a modelar sua existência segundo os códigos em vigor. Isso não impede, entretanto, a introdução de pequenas irregularidades, criando possibilidades de improvisações. Desse modo, os chamados agenciamentos identitários, como fazer parte de um grupo, família, organização, etnia, gênero, fazem com que o sujeito experimente e negocie suas decisões e ações com outros sujeitos e altere sua trajetória de experimentação, mas também permitem metamorfoses no estar no mundo.

Segundo Carvalho (2011, p. 29), é essa potencialidade de afetar e ser afetado que cria as possiblidades de improvisação e de inovação. É pelo poder de afetar e ser afetado, dado pelas condições sócio-históricas, de trabalho, gênero, etnia, família, de estar no mundo, e pelo esgotamento dos sentidos do e no cotidiano que pensamos em outros possíveis, "mostrando uma situação de necessidade e de algo a ser inventado", transformado, metamorfoseado. Para Deleuze (2006), todo ato de pensar é um ato de criação, e, por que não dizer?, de improvisação.

Assim, tratar sobre improvisação nos circos itinerantes tem coerência por três motivos fundamentais. Inicialmente, porque trabalhos com o tema da improvisação têm crescido no campo da gestão. Desse modo, o circo, como organização, justificaria também o uso desse olhar. Em segundo plano, percebe-se, nos estudos realizados, a grande dívida das teorias sobre a improvisação para com alguns campos artísticos, como a música e o teatro, que são pontos cruciais dos espetáculos circenses. Um terceiro motivador é o próprio desenvolvimento da discussão sobre o improviso, que tem direcionado uma atenção cada vez maior aos processos da improvisação, bem como às relações de poder envolvidas em tais processos (Cunha et al., 2014).

\section{OS "BASTIDORES" DA PESQUISA}

O artigo pauta-se na tradição qualitativa de investigação aplicada na análise de multicasos, cujos sujeitos de pesquisa são pessoas trabalhadoras de 31 circos itinerantes localizados nos quatro Estados que constituem a região Sudeste do Brasil, portanto em São Paulo, Rio de Janeiro, Minas Gerais e no Espírito Santo. As organizações circenses que compõem essa pesquisa foram selecionadas de acordo com o critério da bola de neve, técnica que tem sido amplamente utilizada em pesquisas sociais qualitativas (Suri, 2011), em que o acesso a elas ocorreu após indicações feitas por pessoas que mantêm relações com a arte circense, sejam elas circenses ou que trabalham com a linguagem circense, bem como por representantes de sindicatos de artistas.

Nas visitas aos circos, os pesquisadores observaram assistematicamente o cotidiano dos circenses, fazendo anotações sobre seus afazeres diários para, por meio deles, captar modos de ser e fazer que os atores sociais dão às práticas que eles próprios desenvolvem. Essas práticas foram descritas em diários de campo. Conjuntamente às anotações, foram realizadas entrevistas não estruturadas e depois, em um segundo momento de voltas ao campo, realizamos entrevistas semiestruturadas com 116 artistas circenses em torno da vida organizada dos sujeitos de pesquisa, que eram desde proprietários dos circos (que também trabalhavam nos espetáculos) até seus familiares e artistas contratados. 0 período de coleta de dados estendeu-se de junho 
do ano de 2015 a fevereiro de 2016, com visitas para a atualização do tema em pelo menos metade desses circos em 2017.

Os participantes das entrevistas, que foram identificados neste artigo como E01, E02, E03 e assim sucessivamente, eram convidados a falar sobre a vida no circo, que envolveu variados temas, partindo da seguinte provocação: “Conte-nos sobre sua vida no circo". As poucas questões predefinidas após a provocação inicial deixaram os sujeitos de pesquisa com bastante liberdade para improvisar durante suas falas. Vale ressaltar que todas as entrevistas foram gravadas em áudio e, quando permitido, em vídeo. Os dados produzidos pelas entrevistas e observações assistemáticas foram analisados mantendo-se a estrutura discursiva produzida pelos sujeitos. Assim, os trechos selecionados são fiéis, em termos gramaticais, às falas dos circenses.

Interpretamos os materiais por meio da análise de narrativas (Matos, 2017). Realizamos um diálogo entre a temporalidade narrativa e Deleuze. A análise consistiu em considerar a construção de uma narrativa feita pelos próprios pesquisados. Diante do conjunto de discursos obtidos no cotidiano dos circenses, foram realizadas diversas leituras que possibilitaram a identificação de alguns fragmentos discursivos. Criamos categorias de sentido, de modo a conectar as histórias e eventos que tratavam de temas semelhantes. Nesse sentido, a análise de tais enunciados discursivos foi empreendida tendo em vista, especificamente, a sistemática de identificação da análise lexical, dos principais discursos presentes no texto, de temas e figuras, de aspectos implícitos e explícitos nos discursos, da sintaxe discursiva e de aspectos ideológicos presentes nos discursos, conforme demonstrado nas duas próximas seções.

\section{RESPEITÁVEL PÚBLICO! COM VOCÊS, O CIRCO ITINERANTE}

É importante que se compreenda que o produto do circo é o espetáculo. 0 circo vende um serviço que é o entretenimento. Assim, ao se improvisar durante uma apresentação, corre-se o risco de prestar um serviço equivocadamente. 0 circo vende também a manutenção de um modo de existir, isto é, a vida itinerante, nômade. Costa (2018), assim como Deleuze e Guattari (1997), mostra que "o nômade é um desterriorializador por excelência, até se fixa no território, mas somente para extrair daquele espaço as experimentações do corpo, as cores, os sons, os devires, os sonhos de existir e de tornar-se outro, mas logo partem para outras experiências, outros espaços, outros mundos, outros sonhos possíveis de serem sonhados" (p. 8), outras plateias a serem alcançadas, outros espetáculos para serem criados.
O circo sempre vende um serviço - visível - que é o entretenimento, mas, ao mesmo tempo, a ideia implícita de uma vida itinerária, de viagens, lugares, de uma vida sem rotina.

(oo1) 0 circo tem o espetáculo que todo mundo vê. [...] e tem o que não se pensa sobre ele que sempre foi uma ideia de uma vida sem rotina, sem paradas (risos). (E86)

O dono e gestor de um dos circos visitados fala no fragmento acima do tema visível do espetáculo e da ideia (dizível, pensada) de uma vida sem parada e sem rotina, o que, para ele, não é verdade (como indicam os risos no final), pois, para se ter o espetáculo, é preciso, antes de tudo, organizá-lo.

(002) O espetáculo, a nossa apresentação, é para isto que somos circenses. Mas, antes dele acontecer, sempre temos que pensar na viagem, onde montar a lona, conseguir licenças, beijar mão até do padre. (E02)

O fragmento acima evidencia um planejamento de pensar até mesmo a itinerância, para onde ir com aquele espetáculo. Uma certa estratégia de até pedir a benção do padre para se realizar o espetáculo, pois, como apontado em (001), há um imaginário social sobre os circos e seus integrantes. Essas estratégias, para Morais-Storz et al. (2018), aparecem pelo conhecimento do gestor e de uma gerência que se metamorfisa segundo relações de poder. Além disso, essas estratégias evidenciam um agenciamento de identificação entre ser circense e o espetáculo. Agenciamento que define modos de ser dos circenses, modos não comumente aceitos até mesmo pelo padre da cidade.

(003) Você sabe quando o artista não tem família de circo, quando não tem tradição. Não tem areia no sangue. 0 cara pode ser bom no que ele faz, mas não é do circo. [...] Ser de circo é ter tradição de itinerar, de laços familiares, trabalhar como um coletivo. (E25)

No fragmento acima, observamos a construção de um discurso identitário. Família, tradição, itinerância e trabalho coletivo fazem o cotidiano e o espetáculo do circo, temas importantes para quase todos os entrevistados dessa pesquisa. 0 circo como agenciamento identitário, um modo de ser e existir do artista circense tradicional. 
(oo4) [...] Tem vários artistas num circo. Tem circo grandes e pequenos. Tem artistas de variedades. Tem circo que tem grupos de músicas, tem circo que apresenta uma peça encenada. Tem circo que o palhaço é alma do circo. (E31)

O entrevistado E31 demonstra possiblidades artísticas dos circenses, e subentendem-se também os espetáculos a serem apresentados. Bolognesi (2005) faz uma caracterização para diferenciar os circos a partir de seus espetáculos. 0 circoteatro é entendido como espetáculo em que são apresentados diversos gêneros teatrais. 0 circo de atrações seria o espetáculo convencional, em que são apresentadas várias habilidades, como números de malabarismo, contorcionismo, acrobacias, ilusionismo, animais amestrados (hoje proibidos) etc. Já o circo de variedades caracteriza-se pela apresentação de números de habilidades associados a shows, apresentação de grupos musicais, cenas teatrais cômicas etc.

Os espetáculos são montados e mantidos por um grupo de pessoas que vão desde as próprias famílias que vivem nos circos até pessoas contratadas individualmente, como artistas apenas para shows. Quaresma et al. (2014) mostram que hoje há circos que fazem alianças estratégicas para terem em seus espetáculos nomes de artistas famosos, personagens considerados da moda, para a atração de público. Essas alianças aparecem para assegurar a sobrevivência dos circos perante a televisão e internet. Assim, crianças do Crato (CE) poderiam ver in loco a personagem Galinha Pintadinha, a porca Peppa e até mesmo a Turma da Mônica.

Em um dos espetáculos assistidos pelos pesquisadores, havia a "cover da cover" da Galinha Pintadinha, que, em determinada parte do show, dançava e fazia a plateia infantil delirar. Em outro momento do show, a galinha cai do tablado montado no picadeiro. A plateia se assusta, o narrador grita, a música para. Há um silêncio quase mortal. Mas, logo depois, a galinha levanta (com certa dificuldade, pela fantasia) e sai dançando com a plateia. Perguntados sobre esse procedimento, os entrevistados nos dizem que tudo ocorreu na base do improviso, pois não fazia parte da cena:

(005) o ator caiu do tablado quase matando a plateia de susto, teve gente que gritou, criança chorou, mas o ator improvisou, levantou e saiu galinhando com as crianças da plateia. A gente acabou pondo isto no espetáculo e melhorou, né? Mas não tinha isso antes, não. (E57)

\section{A IMPROVISAÇÃO COMO AGENCIAMENTO IDENTITÁRIO NO CIRCO}

(oo6) O senhor sabe, né?! O circo tem um encantamento... Mas não é só música e variedade, música e show, música e teatro, música e riso. É magia, mas não só isso. (E20)

O fragmento (006) explicita muito bem que encenação e música são importantes na construção dos espetáculos circenses. Ele resume as diversas entrevistas em que música e teatro/show/variedade são coprodutores do riso, da magia que há no circo. Nos circos visitados em geral, havia mistura de músicas e teatro, pequenas representações cômicas, havia também música e expressões corporais diversas, como danças e acrobacias. A música e o teatro criam ambientes que prendem a atenção do público e podem definir o efeito do espetáculo sobre a audiência. Mas o entrevistado E2o também nos lembra de que o circo não é só encantamento. Ele é uma organização onde vivem e trabalham pessoas, onde há relações de poder, contratos trabalhistas, gerenciamento de um cotidiano itinerário que cria uma rotina de desmontar a lona-viajar-montar a lona, visitar as autoridades, fazer propaganda, comer, vestir, ensaiar e, por fim, representar.

Um discurso que se evidencia durante a narrativa em tela, assim como em diversas outras, é o quanto a improvisação se volta para o público. Nesse ponto, chamam a atenção algumas dificuldades dos artistas (principalmente os palhaços) durante os espetáculos, que lidam com a interação direta com a plateia:

(oo7) O palhaço é a alma do circo, né? (E35)

(oo8) 0 palhaço [...] troca com o público a todo momento. (E11)

(oo9) Tem que ser malicioso [...] tem que ter um dom que já nasce com a gente. (E6)

(010) [...] porque isso é a coisa mais difícil o palhaço aprender, é da interatividade pra plateia e artista, porque você tem que saber brincar sem ofender, sem deixar a pessoa... Levar como brincadeira e não como ofensa, então você tem que ter esse "time", entendeu, você saber até onde a brincadeira vai. (E22) 
Os fragmentos acima chamam atenção para duas dimensões, uma temporal e outra espacial. No plano do enunciado, a localização temporal remete ao presente. Ter o "time" (palavra inglesa para designar tempo) “a todo momento". Entretanto, ter o time a todo momento diz muito mais. É uma metáfora que trata de um conjunto de saberes-fazeres. Os entrevistados E6 e E22 defendem ideias diferentes sobre como se adquirem essas “malícias”, certo limite na interação. Ao se improvisar durante uma apresentação, corre-se o risco de prestar um serviço equivocadamente, como evidenciado no fragmento (010). Brincadeira e ofensa podem ser lados de uma mesma moeda, criando algumas dificuldades dos artistas durante os espetáculos. Brincadeira e ofensa são dispositivos (Deleuze, 1991; Foucault, 1979) que o palhaço pode usar para fazer a plateia (re)agir. Esse (re)agir da plateia reterritorializa o palhaço, que continua o show com novas brincadeiras, ou o desterritorializa e produzirá uma improvisação para redesterritorializar a plateia e continuar o show.

O time entre desterritorialização e reterritorialização deve ser mínimo. A plateia não deve refletir sobre a ofensa. Sua resposta já foi dada, e o palhaço tem o dever de reconduzir seu público às próximas brincadeiras. A reação da plateia obriga-o avançar com outra brincadeira (reterritorialização) ou ele tem que retroceder, e sua liberdade de ação será tolhida, provocando uma desterritorialização nesse artista. Assim, o time age como limitação que pode também constranger o sujeito artista (nesse caso, o palhaço), tolhendo sua ação.

0 palhaço trabalharia em uma corda bamba entre poder brincar e poder ofender, e esse equilíbrio é aprendido com a vivência circense, como explicita E22, com a possibilidade de o ofício de palhaço ser aprendido no sentido da prática. Ou, como E6, trata-se de um dom, que, por seu turno, pressupõe a ideia de que seja uma dádiva, implicitamente associada ao nascimento, e mesmo de um agenciamento identitário. Pontos de vista à parte, ambos chegam à mesma frase, às mesmas palavras, ao mesmo vocabulário imperativo: "tem que ter". Essa é a premissa para conseguir "brincar sem ofender" e "saber até onde a brincadeira vai”. Para ambos os narradores, o momento presente, quando é tomada a decisão sobre o futuro (saber até onde se irá com a brincadeira), precisa de uma história no e com o circo. Ou se trata de um "nascimento" ou de um aprendizado, que ocorreu e ocorre. Com relação ao aprendizado, Crossan e Hurst (2006) esclarecem que a improvisação demanda certa base sólida de habilidades técnicas e experiência nos domínios nos quais será aplicada. Além disso, para os autores, a questão do tempo é relevante para o improviso, pois remete à espontaneidade.

No decorrer dos espetáculos, ficou nítido que a dimensão física do espaço pode intensificar o constrangimento.
Nos circos pesquisados, o palco fica no centro do redondel, cercado à sua frente por cadeiras dispostas como um semicírculo, cuja posição objetiva maximizar a visibilidade da plateia. Nos espetáculos, os circenses usam vestimentas próprias, com brilhos e cores que, na hora da apresentação, são ressaltadas pelas luzes em diversas tonalidades voltadas para o palco. Frequentemente, muita intensidade e jogos de luzes intermitentes cintilam, chamando ainda mais a atenção para o palco. Os bastidores, também chamados de "reservado", são tapados por uma cortina, impedindo a plateia de ver os artistas antes de subirem ao palco. Enquanto os artistas se apresentam, durante todo o tempo, a plateia permanece na penumbra, dificultando, inclusive, aos espectadores enxergar as pessoas que estão próximas a eles.

Entretanto, o palco é não apenas central do ponto de vista físico, mas levado a ser o centro das atenções e, portanto, para onde a plateia dirige seu olhar e, sobre ele, o artista, que, durante seu número, fica exposto contínua e intensamente. Nesse sentido, essa superexposição tem como produto efeitos disciplinares, como ilustrado por Foucault (1979), pois submete os artistas ao controle, que os levará a controlarem a si próprios. Nesse caso, o controle é feito pelo público, que tolhe a liberdade de atuação do artista, o qual, durante os espetáculos, está sempre em “interatividade” e em exposição.

Em outras palavras,

(011) se o palhaço não sente a troca com o público, se você não sente que a pessoa chegou até você, você sai derrotado, você fala "meu, [...] ninguém olhou pra mim, ninguém riu de mim". (E11)

E não chamar a atenção da plateia, não interagir com ela, é sinônimo de derrota, pois o esquete não produziu a resposta desejada. A plateia desterritorializou o artista, não olhou para ele, não participou do número e muito menos riu dele e de sua interpretação. Segundo E11, existe, implicitamente, um jogo entre a plateia e o artista. Nele, existem derrotados e vitoriosos. Fica claro, pelas hipérboles "ninguém olhou" e "ninguém riu”, que ser olhado (ou seja, manter a atenção dos presentes) e fazer rir é vencer. Nesse jogo, a figura do palhaço brinca para receber de volta o olhar e o sorriso: essa é a "troca".

Por outro lado, apesar de se sentir constrangido, incomodado, embaraçado porque “ninguém riu”, há sempre a possiblidade de improvisar e de chamar a atenção da plateia, reterritorializando o espetáculo, como nos disseram alguns palhaços sujeitos de pesquisa: 
(012) [...] Então cê brinca, brinca com as criança. Sacaneia as pessoas... (E6)

(013) Então eu brinco, brinco com as crianças. Eu subo na arquibancada e brinco com um e com outro, mesmo quando tô levando a comédia, eu brinco com um e com outro, faço uma interação [...] (E45)

Os verbos escolhidos pelos circenses E45 e E6 denotam o caráter da interação com os diversos públicos. As restrições percebidas como impostas pela audiência são tencionadas. Brincar, principalmente com as crianças (e até com alguns adultos), pode fazer o show continuar sua organização inicial. A magia do circo parece funcionar melhor nas crianças, que respondem mais espontaneamente às brincadeiras.

Uma vez no espaço do palco, os entrevistados se mostraram capazes de encaminhar a interação de diversas formas possíveis dentro do tempo do espetáculo. No circo, a arte é circunscrita a um espaço e um tempo:

(014) Acho que a única coisa que o pessoal tem uma preocupação ainda é com o tempo, porque como a gente é duas horas de espetáculo [...] mas você tem a liberdade dentro do tempo, se você quiser fazer mil coisas dentro daquele tempo tá beleza, acho que tem que tomar tempo, ainda mais porque é muito improviso, às vezes não tem como você, igual eu falei, não tem como você saber a reação da galera. (E21)

(015) [...] se você demora muito, faz aquela coisa de dar barriga no público que a gente diz aqui, né?, o público tá assim, aí você demora, aí a pessoa vai sentando e dá aquela barriguinha, então você já perdeu o público. (E52)

(016) Quando eu vejo que o vácuo tá... A entrada não tá agradando muito, nós picoteia ela, corta ela. Tem pouca gente, que nem a gente tenta agradar, se vê que não tá, vamo trabalhar mais rápido, entendeu?, pra não virar cansativo pro público. Então cê tem que trabalhar com a malícia, se tá agradando, cê vai empurrando. (E46)

Observa-se, na narrativa acima, como os sujeitos circenses se relacionam diferentemente com o tempo do espetáculo. Tanto
E21 quanto E52 evidenciam um terceiro agente, "o pessoal” ou "a pessoa", para se referirem a um personagem coletivo, que gere o espetáculo, que se preocupa com o tempo. A limitação do tempo do circense relaciona-se à percepção dos artistas de que o espetáculo está ou não agradando ao público. A ideia é agradar a todo custo o público, a galera, seja ela grande ou pequena. O espetáculo se metamorfisa, então, em várias possiblidades: encurtando, empurrando, apressando, picoteando, que são agenciamentos que possibilitam maliciosamente a improvisação de ocorrer para se "fazer mil coisas dentro daquele tempo" de duas horas. Já E46 organiza suas frases de modo a expor o tema da percepção do público, mas sem se remeter a um terceiro agente, que se preocuparia com o fato de sua apresentação ser demorada ou não.

Devido à complexidade do cotidiano dos circos, a improvisação surge de diversos grupos de artistas, conforme pode ser visto no trecho a seguir, produzido por Eo8: “O apresentador tá ali... Se dá alguma coisa errada você tem que improvisar, você tem que dar um jeito pro público não perceber". Existe, em verdade, um trabalho em conjunto. Enquanto o apresentador, também chamado de "mestre de pista”, pode estar improvisando uma nova sequência sem o público perceber, o artista sabe que se “[...] colocou a música e não entrou a person, o palhaço sempre tem que tá pronto pra qualquer coisa, [...] um acidente ali, qualquer coisa, que dê pra cobrir esse vácuo. Tem que tá pronto pra tudo" (E26).

Assim, o discurso da improvisação conecta-se novamente com a possiblidade de leitura dos artistas da afetação, ou não, da plateia. No caso do apresentador, as adaptações são necessárias diante de um pensamento inicial. Se existe algo que deu errado em relação ao que era planejado, ele precisa criar outras possiblidades, improvisando nova sequência, criando metamorfoses ao anteriormente desenhado, para que o espetáculo continue sem afetar a percepção do público. Entre as coisas erradas, pode-se enumerar, nas falas do palhaço, a ausência de alguma pessoa que deveria ter entrado no palco, e mesmo algum acidente. As coisas erradas criam “vácuo”, afetam o padrão planejado, mas criam possíveis. É preciso lembrar que o possível é substituível, intercambiável:

0 possível é sempre limitado e condenado a repetir a partir de uma margem de variação, que, com a pretensão de abarcar o um e o outro, é sempre dual, mas jamais múltipla. De repente, quando uma série de possíveis se esgota e o impossível é atingido, tudo se transforma em acontecimento, cada movimento é uma metamorfose. (Agostinho, 2017, p. 623)

O vácuo e afetação ou não da plateia circense cria possíveis que metamorfisam o espetáculo segundo projetos, 
preferências, objetivos, identidades, número de artistas, porte do circo, dos artistas terem "que tá pronto pra tudo". Agostinho (2017) ainda nos lembra que esses possíveis são limitados, mas intercambiáveis entre si, e supõe a exclusão, a substituição, a adaptação, a variação de algo no cotidiano daquele grupo social, seja um circo, uma ONG, uma organização privada, pública etc. O fato de o artista estar "pronto" para tudo denota essa necessidade de adaptação, reconhecidamente um improviso. Adaptação e improviso são processos independentes, contudo, ocasionalmente, a necessidade de adaptação é tão urgente que os artistas circenses não têm tempo para organizar um novo plano antes da respectiva implementação e devem fundir o planejamento e a execução, isto é, devem improvisar (Abrantes, Passos, Cunha, \& Santos, 2018).

Assim, este estudo buscou pensar a improvisação partindo empiricamente de circos itinerantes, de sua gestão e de seu espetáculo. A preferência assumida segue, então, por outra forma de escrita, mais coerente com o cotidiano do circense, mais voltada para os lugares onde a improvisação acontece, mais próxima da vida do artista. Os imprevistos que acontecem no cotidiano circense vividos pelos sujeitos produzem uma desterritorialização momentânea, mas oportunizam a esses sujeitos improvisarem, reterritorilizando o circo, uma vez que o show precisa continuar. E esse continuar tem duas possibilidades: uma de continuar com a itinerância e outra de que o espetáculo tem que continuar e terminar em seu horário marcado.

\section{CONSIDERAÇÕES FINAIS}

Neste artigo, buscamos pensar a improvisação, tema importante para a Administração e que comumente tem sido tralhado com base em metáforas. Jazz e teatro são as metáforas mais utilizadas nos Estudos Organizacionais para referenciar o improviso. Porém, levantamos aqui as limitações da utilização de metáforas para explicar os processos de improvisação. As metáforas, seja a do jazz, teatro ou outras, seriam formas ingênuas de abordar o tema, uma vez que nenhum improviso é neutro politicamente.

Visto isso, buscamos trazer o conceito de metamorfose, de transformação, para estudar a improvisação. Baseados em Deleuze, trabalhamos os agenciamentos, as possiblidades do cotidiano, não para fechar a gestão em um modelo, mas para buscar abrir potencialidades de saber-fazer, potencialidade de afetar e ser afetado no e pelo cotidiano das pessoas.

Seguindo nessa linha analítica, observamos que a improvisação, para os circenses itinerantes, aparece pelo nomadismo dessa arte. Ser itinerante produz diversos, múltiplos circos que podem ser o mesmo, mas que muda conforme as condições sócio-históricas. Que se desterritorializa constantemente, mas que é um território para os artistas circenses. As pessoas do circo lidam cotidianamente com contradições entre ser ou não recebido pelas autoridades locais (inclusive pelo padre), ter espaço para montar a lona ou não, ter ou não público, ser aplaudido ou vaiado, o riso ou a tristeza, o sobressalto da surpresa ou a mesmice de sempre, a confiança naquela arte ou a desconfiança rotulada com preconceitos. Essas contradições são resultados das relações de poder com que os atores circenses e a gestão do circo convivem em sua itinerância. Nesse sentido, observamos que itinerância, família, tradição e trabalho coletivo fazem o cotidiano e o espetáculo do circo. 0 circo ecomo agenciamento identitário cria várias possibilidades de ser artista e trabalhar, assim como cria díspares espetáculos em distantes lugares com diferentes públicos.

O improvisar nesses circos pode surgir de uma espécie de "dom" ou de um aprendizado, mas se conecta às pesquisas da improvisação nos Estudos Organizacionais na medida em que opera uma forma de compressão entre passado, presente e futuro, ou seja, depende de aprendizados passados, em determinado momento presente, objetivando consequências no futuro. É essa base de técnicas e habilidades construídas que permite ao artista afetar ou não seu público. 0 artista "tem que ter" a noção de até onde pode ir a brincadeira, até onde a restrição externa pode ser subvertida, ressignificada e entendida como desrespeito. Entre aprendizado e dom, há uma certeza: a dificuldade e a necessidade de se alcançar o "time”, ou o lugar entre a brincadeira e a ofensa, que ocorre muitas vezes por meio da improvisação no palco.

Os constrangimentos transmitidos pela plateia, somados à condição arquitetural do palco, remetem ao dispositivo de poder alardeado por Foucault $(1977,1979)$. À semelhança das prisões, no que tange aos efeitos do poder, o palco induz nos artistas um controle interno sobre sua própria ação, que acontece na interação, no tempo presente da relação. Durante a apresentação do artista, o público the tolhe a liberdade, pois o constrange, estando aquele sempre em "interatividade" e também superexposto. Nesse sentido, o palco e a plateia formam um aparelho onde se realiza um jogo, onde o palhaço brinca para receber de volta o olhar, o sorriso, mas também onde os elementos para portar-se são apresentados. Assim, o fluxo dar e receber é que define, para os artistas, a possibilidade de se sair vitorioso ou não. Nesse ínterim, o artista também constrange quando "sacaneia".

Um furo, um vácuo no espetáculo possibilita aos artistas, seja ele apresentador ou palhaço, criar e transformar o espetáculo 
em outro. Uma metamorfose que não pode afetar o público, mas que é (re)conhecida por quem é do circo e que deve estar preparado para tudo. Metamorfose que produz improvisações, que podem ser repetidas, aprendidas de outras experiências, outros shows, mas que não deixam de desenhar outro espetáculo.

Como forma de contribuir para os estudos do campo, afirmamos, baseados em Deleuze e Deleuze e Guattari, que há um esgotamento dos modelos de gestão. Mas essa falência dos modelos pode ser apenas uma condição para novas possiblidades e outras modalidades do gerir. A falência e o esgotamento mostram uma situação de necessidade e de que algo precisa ser inventado, criado. Problematizar a improvisação permite pensar em estratégias de resistência mediante o instituído, a linha dura. A improvisação como linha de fuga, em que há um escape diante do instituído, ao que é padrão e norma, buscando, mesmo na intenção, escapar, fazer diferente. Assim, refletir a partir desses autores é pensar em uma possível ética da improvisação, isto é, partir da ideia de uma contínua improvisação cotidiana, em que os sujeitos experimentariam continuadamente atos de criação no dia a dia, no trabalho, na sua sobrevivência.

\section{NOTA DE AGRADECIMENTO}

Agradecemos ao CNPq pelo financiamento da pesquisa e à CAPES pela concessão de apoio ao projeto pelas bolsas financiadas.
Aguiar, A. R. C., \& Carrieri, A. P. (2016). "Água de lona" e "Sangue de serragem" nos discursos de sujeitos circenses. Organizações \& Sociedade, 23(77), 247-262. doi:10.1590/1984-9230774

Arantes, F. P., Freitag, M. S. B., \& Santos, E. L. S. (2018). Improvisação e aprendizagem de empreendedores informais: A experiência de empreendedores feirantes. Revista de Empreendedorismo e Gestão de Pequenas Empresas, 7(3), 1-31. doi:10.14211/regepe.v7i3.921

Bolognesi, M. F. (2005). O riso no circo: A paródia acrobática. Urdimento-Revista de Estudos em Artes Cênicas, 1(7), 67-74. doi:10.5965/1414573101072005067

Buras, N. A. (2017). "Building on the ideas as opposed to tearing down ideas": Improviser facilitators' contributions to workplace learning. The Online Journal of New Horizons in Education-April, 7(2), 54-61. Recuperado de https://www.tojned.net/journals/tojned/ articles/v07io2/v07io2-06.pdf

Carvalho, J. D. (2011). Gilles Deleuze e Guimarães Rosa, uma conexão entre filosofia e literatura: 0 devir, o duplo e a metamorfose. Aisthe, 5(7), 27-40. Recuperado de https://revistas.ufrj.br/index.php/ Aisthe/article/view/286/306

Cassell, C., \& Bishop, V. (2018). Qualitative data analysis: Exploring themes, metaphors and stories. European Management Review, 16(1), 1-13. doi:10.1111/emre.12176

Cornelissen, J. P. (2005). Beyond compare: Metaphor in organization theory. The Academy of Management Review, 30(4), 751-764. doi:10.2307/20159166

Costa, D. W. (2018). Nomadismo como potência de sonhar: 0 nômade e sua máquina de guerra. ARTEFACTUM - Revista de Estudos em Linguagens e Tecnologia, 16(1), 1-9. Recuperado de http://artefactum. rafrom.com.br/index.php/artefactum/article/view/1635/748

Costa, L. B. (2006). O Ritornelo em Deleuze-Guattari e as três éticas possiveis. Recuperado de http://coral.ufsm.br/gpforma/2senafe/ PDF/oo5e2.pdf

Crossan, M. M., \& Hurst, D. K. (2006). Strategic renewal as improvisation: Reconciling the tension between exploration and exploitation. In J. A. C. Baum, S. D. Dobrev, \& A. Van Witteloostuijn (Eds.). Ecology and Strategy - Advances in Strategic Management (pp. 273-298). Bingley: Emerald Group Publishing Limited.

Crossan, M., \& Sorrenti, M. (2002). Making sense of improvisation. Advances in Strategic Management, 14, 155-180. Recuperado de https://ir.stonybrook.edu/xmlui/bitstream/handle/11401/8165/ crossanandsorrenti1997. $p d f$ ? sequence $=3$

Cunha, M. P. (2002). All that jazz: Três aplicações do conceito de improvisação organizacional. RAE-Revista de Administração de Empresas, 42(3), 1-7. doi:10.1590/So034-75902002000300004

Cunha, M. P., Clegg, S. R., Rego, A., \& Neves, P. (2014). Organizational improvisation: From the constraint of strict tempo to the power of the Avant $\square$ Garde. Creativity and Innovation Management, 23(4), 359-373.

Cunha, M. P., Clegg, S. R., Rego, A., \& Story, J. (2013). From the physics of change to Realpolitik: Improvisational relations of power and resistance. Journal of Change Management, 13(4), 460-476. doi:10. 1080/14697017.2013.851923

Deleuze, G. (1991). Foucault. São Paulo, SP: Brasiliense. 
Deleuze, G. (2006). Diferença e repetição. Rio de Janeiro, RJ: Graal.

Deleuze, G. (2013). El saber: Curso sobre Foucault. Buenos Aires, Argentina: Cactus.

Deleuze, G., \& Guattari, F. (1995a). Mil platôs: Capitalismo e esquizofrenia (Vol. 1). São Paulo, SP: Editora 34.

Deleuze, G., \& Guattari, F. (1995b). Mil platôs: Capitalismo e esquizofrenia (Vol. 2). São Paulo, SP: Editora 34.

Deleuze, G., \& Guattari, F. (1997). Mil platôs: Capitalismo e esquizofrenia (Vol. 5). Rio de Janeiro, RJ: Editora 34.

Flach, L. (2012). A rota das cervejarias artesanais de Santa Catarina: Analisando improvisação e aprendizagem. Revista Eletrônica de Gestão Organizacional, 10(3), 567-594. Recuperado de https:// periodicos.ufpe.br/revistas/gestaoorg/article/viewFile/21633/18325

Foucault, M. (1977). Vigiar e punir. Petrópolis, RJ: Vozes.

Foucault, M. (1979). Microfísica do poder. Rio de Janeiro, RJ: Edições Graal Ltda.

Hadida, A. L., Tarvainen, W., \& Rose, J. (2015). Organizational improvisation: A consolidating review and framework. International Journal of Management Reviews, 17(4), 437-459. doi:10.1111/ ijmr.12047

Hatch, M. J., \& Weick, K. E. (1998). Critics' corner: Critical resistance to the jazz metaphor. Organization Science, 9(5), 600-604. doi:10.1287/ orsc.9.5.600

Kafka, F. (2000). A metamorfose. São Paulo: Brasiliense.

Kravchenko, S. A. (2017). Metamorphoses: Essence, increasingly complex types, place in sociology of knowledge. Sociological Studies, 10(10), 3-14. doi:10.7868/S0132162517100014

Leybourne, S. A., Lynn, G., \& Vendelø, M. T. (2014). Forms, metaphors, and themes: An introduction to the special issue on organizational improvisation. Creativity and Innovation Management, 23(4), 353 358. doi:10.1111/caim.12093

DeLuca, G. De, Rocha-de-Oliveira, S., \& Chiesa, C. D. (2016). Projeto e metamorfose: Contribuições de Gilberto Velho para os estudos sobre carreiras. Revista de Administração Contemporânea, 20(4), 458-476. doi:10.1590/1982-7849rac2016140080

Matos, M. F. B. (2017). Produção de sentido e efeitos de protagonismo na cobertura de um jornal local: Análise de narrativas. ÂNCORARevista Latino-americana de Jornalismo, 4(2), 74-92. doi:10.22478/ ancora.v4n2p74-92
Morais-Storz, M., Platou, R. S., \& Norheim, K. B. (2018). Innovation and metamorphosis towards strategic resilience. International Journal of Entrepreneurial Behavior \& Research, 24(7), 1181-1199. doi:10.1108/ IJEBR-11-2016-0369

Müller, M. (2018). 'Brandspeak': Metaphors and the rhetorical construction of internal branding. Organization, 25(1), 42-68. doi:10.1177/1350508417710831

Parker, M. (2011). Organizing the circus: The engineering of miracles. OrganizationStudies,32(4),555-569.doi:10.1177/0170840611403668

Quaresma, E. A., Jr., Silva, E. R., \& Carrieri, A. P. (2014). As alianças estratégicas no picadeiro da arte/negócio circense. Revista de Administração Mackenzie, 15(3), 101-131. doi:10.1590/1678 69712014/administracao.v15n3p101-131

Sanabria, M., \& Moreno, D. (2018). A contribution to the understanding of emerging strategies in organizations through the concept of improvisation and the musical metaphor. Revista Facultad de Ciencias Económicas: Investigación y Reflexión, 26(1), 27-68. doi:10.18359/rfce.2686

Soler, R. D. V. (2016). Biopolítica e direitos dos governados em Michel Foucault. Anais do V Colóquio Internacional IHU, São Leopoldo, RS.

Suri, H. (2011). Purposeful sampling in qualitative research synthesis. Qualitative Research Journal, 11(2), 63-75. doi:10.3316/QRJ1102063

Vera, D., \& Crossan, M. (2004). Theatrical improvisation: Lessons for organizations. Organization Studies, 25(5), 727-749. doi:10.1177/0170840604042412

Vera, D., Nemanich, L., Vélez-Castrillón, S., \& Werner, S. (2016). Knowledge-based and contextual factors associated with R\&D teams' improvisation capability. Journal of Management, 42(7), 1874-1903. doi:10.1177/0149206314530168

Weick, K. E. (1979). The social psychology of organizing. Nova York: McGraw-Hill.

Weick, K. E. (2002). A estética da imperfeição em orquestras e organizações. RAE-Revista de Administração de Empresas, 42(3), 6-18. doi:10.1590/So034-75902002000300002

Zourabichvili, F. (2005). Deleuze and the question of literality. Educação \& Sociedade, 26(93), 1309-1321. doi:10.1590/S010173302005000400012

Zourabichvili, F., \& Goldstein, V. (2004). O vocabulário de Deleuze. Rio de Janeiro, RJ: Relume Dumará.

\section{CONTRIBUIÇÃO DOS AUTORES}

Os autores declaram que todos tiveram contribuição no desenvolvimento do estudo. A conceitualização e abordagem teóricametodológica foi trabalhada principalmente pelo Alexandre Carrieri e pela Ana Rosa Aguiar. A revisão teórica (levantamento de literatura) e a coleta de dados foram realizadas por todos os autores. A análise de dados foi conduzida principalmente pelo Edson Quaresma Júnior. Todos os autores atuaram na redação e revisão final do manuscrito. Agradecemos também a professora Raquel Barreto pela leitura crítica do estudo. 